\title{
TRADUÇÃO COLETIVA E ILUSTRAÇÃO: ESTÉTICA DA CRIAÇÃO CINEMATOGRÁFICA EM JANE AUSTEN
}

\author{
Augusto Rodrigues da Silva Junior* \\ Lemuel da Cruz Gandara** \\ Universidade de Brasília
}

\begin{abstract}
Resumo: A partir de recortes metonímicos dos romances Razão e sentimento (1811), Orgulho e preconceito (1813), Emma (1815) e Persuasão (1817), escritos pela autora inglesa Jane Austen (1775-1817), propomos fazer uma análise comparativa entre os textos literários, as ilustrações feitas por Hugh Thomson no final de século XIX e as imagens fílmicas criadas entre os anos de 1995 e 2005. Nosso objetivo é confrontar passagens para encontrarmos aproximações e distanciamentos dialógicos entre elas. Tal perspectiva revela as interpretações realizadas por diversos leitores ao longo dos anos e as recepções da escritora inglesa em contextos e meios diversos. Nossa reflexão crítica e teórica tem como base os estudos do filósofo russo Mikhail Bakhtin sobre a estética da criação literária e se amplifica nos conceitos de cinema literário, tradução coletiva e estética da criação cinematográfica.
\end{abstract}

Palavras-chave: Jane Austen. Ilustração. Mikhail Bakhtin. Tradução coletiva.

\section{Introdução}

Os diversos campos artísticos, bem como das atividades humanas, realizam-se na utilização de signos. A arte é parte do mundo, mas é um mundo em si mesma. A vida, por sua vez, não cabe no cotidiano e apresenta modalidades artísticas capazes de fazerem do presente, história. Cabe a nós realizar a análise do cinema literário e sua tradução coletiva no campo de

\footnotetext{
(c) (1) Esta obra está licenciada sob uma Creative Commons - Atribuição 4.0

* Professor Adjunto III de Literatura Brasileira da Universidade de Brasília. Phd em estudos lusófonos pela Universidade do Minho e Doutor em Literatura Comparada pela Universidade Federal Fluminense (2008). Atua com os conceitos de: Estética da criação cinematográfica; Artes Cinêmicas; Tradução coletiva; Cinema literário; o problema do hífen; performance e teatro de terreiro. Poeta premiado no Concurso de Poesia Fernando Mendes Vianna e no Concurso Nacional de Ensaio - Prêmio Cassiano Nunes. E-mail: augustorodriguesdr@gmail.com.

** Doutorando em Literatura e práticas sócias pelo Programa de Pós-Graduação em Literatura da Universidade de Brasília (Póslit-UnB). Pesquisador Bolsista CAPES. Mestre em Literatura pela mesma instituição. Bacharel em Estudos literários e licenciado em Língua portuguesa pela Universidade Federal de Goiás. Desenvolve pesquisas que relacionam literatura e cinema, com ênfase em tradução coletiva, cinema literário e artes cinêmicas. É artista visual e ilustrador. E-mail: gandara21@hotmail.com.
} 
uma estética da criação cinematográfica. Neste espaço, analisamos pelos ângulos das relações que se estabelecem entre livro, ilustração, filme.

No horizonte da recepção, o texto literário avança no tempo, em distintos contextos, cruzando vários fluxos, sempre a acrescentar novas possibilidades de compreensão. Essas instâncias que facultam a dinamicidade literária fazem parte do grande tempo das artes. Esse tempo, pleno de cronotopos, é propício ao diálogo e, nele, leitores e expressões artísticas reverberam a palavra viva, a imagem movente, um universo de respondibilidades que se bifurcam:

E toda a minha vida é uma orientação nesse mundo; é reação às palavras do outro (uma reação infinitamente diversificada), a começar pela assimilação delas (no processo de domínio inicial do discurso) e terminando na assimilação das riquezas da cultura humana (expressas em palavras ou em outros materiais semióticos). (BAKHTIN, 2003, p. 379).

Ao coadunarmos literatura e artes visuais, conjecturamos inúmeras perspectivas que expandem o texto publicado numa tensa arena dialógica. Nesse sentido, ao abordamos os livros da autora inglesa Jane Austen (1775-1817), deparamos com um singular processo de recepção e de releituras ao longo do tempo. Neste momento, merece especial destaque o trabalho de Hugh Thomson, que ilustrou todas as obras durante a década de 1890 e que, de certa forma, expandiu uma visão figural e figurinista do universo austeniano.

As ilustrações formam a primeira grande parceria entre os romances austenianos e outros materiais semióticos. Esta questão, um século depois, na década de 1990, foi retomada pela arte cinematográfica. Dessa forma, percebemos um desenvolvimento dialógico não apenas da publicação na época da autora, mas, também, das imagens que ela deflagra. A imagem é sempre uma resposta ao escrito - uma forma unilateral de recepção e de tornar o texto receptivo.

Para discutirmos essa rotatividade da palavra romanceada que se multiplica nas imagens de leitores-artistas, ressaltamos em nossa discussão outras ideias de Bakhtin, como seus estudos sobre o autor, o excedente de visão e o signo. Esses instrumentos de análise nos ajudam a argumentar sobre o livro com ilustração, a imagem fílmica, as tentativas de aproximação visual da época da autora e aquilo que o alheio faculta no contexto da recepção criadora. Dessa maneira, este conjunto pensamental nos oferece a base epistemológica para nossos conceitos (in progress): cinema literário, tradução coletiva e estética da criação cinematográfica.

\section{Direções bakhtinianas: do signo ao grande tempo}


Em Marxismo e filosofia da linguagem, Bakhtin (Voloshinov ${ }^{1}$ ) desenvolve sua ideia sobre o signo. O filósofo afirma: "ao lado dos fenômenos naturais, do material tecnológico e dos artigos de consumo, existe um universo particular, o universo de signos" e acrescenta: “(...) todo signo está sujeito aos critérios de avaliação ideológica. O domínio do ideológico coincide com o domínio dos signos: são mutuamente correspondentes. Ali onde o signo se encontra, encontra-se também o ideológico" (2006, p.30). O signo, então, se desenvolve segundo a ideologia, no campo das imagens, em seus campos de enunciação. Esse discurso, que significa, é motivado pelas relações dialógicas estabelecidas:

É preciso insistir sobre o fato de que não somente a atividade mental é expressa exteriormente com a ajuda do signo (assim como nos expressamos para os outros por palavras, mímica ou qualquer outro meio) mas, ainda, que para o próprio indivíduo, ela só existe sob a forma de signos. Fora deste material semiótico, a atividade interior, enquanto tal, não existe. Nesse sentido, toda atividade mental é exprimível, isto é, constitui uma expressão potencial. (BAKHTIN; VOLOSHINOV, 2006, p. 50)

Na concepção bakhtiniana, o signo é responsável pelos discursos expostos no mundo exterior e também pela forma como o indivíduo o entende em seu interior. Assim, só é possível se comunicar por meio de signos. Ele também está intrinsicamente conectado com a ideologia do contexto. Então, num processo de intersemiose em que a obra literária nasce primeiro, podemos considerar que as ilustrações e os filmes permitem continuar e atualizar o enunciado original. O que vem depois são traduções coletivas. No caso dos livros ilustrados na década de 1890 - um projeto editorial, um recurso tipográfico num período de maior circulação do folhetim e de maior desenvolvimento tipográfico. Quanto ao cinema, um conjunto de leitores realizam esta tradução: roteirista, diretor, figurinista, fotógrafo, dentre outros.

Ora bem, se o signo é ideológico ele está em função de um tempo. No caso de obras literárias de Austen, ele recupera uma época, pois a autora escreveu sobre e para as leitoras(res) de seu período nos limites da sua compreensão. Assim, a envergadura de sua poética apresenta um cronotopo intimamente ligado ao seu espaço em que "[...] ocorre a fusão dos indícios espaciais e temporais num todo compreensivo e concreto. Aqui o tempo condensa-se, comprime-se, torna-se artisticamente visível [...] os índices do tempo transparecem no espaço, e o espaço reveste-se de sentido e é medido como tempo" (BAKHTIN, 1998, p. 211).

\footnotetext{
${ }^{1}$ A obra foi escrita em parceria Valentin Voloshinov, um dos membros do que ficou conhecido como Círculo de Bakhtin.
} 
Austen, geralmente, não reporta o ano da ação no interior de seus romances. A temporalidade se dá na contagem das semanas, dos meses e dos anos, ou até mesmo das estações - tão bem marcadas na atmosfera inglesa. Mesmo assim, é possível encontrar a cronologia histórica nas obras: no tratamento dado aos personagens, nos habitus, nos detalhes sociais típicos do gênero romanesco.

As ilustrações que analisaremos surgiram a partir do contato tradutivo entre Hugh Thomson e o texto de Austen. Dessa forma, pensamos a recepção e a tradução. Tudo começa com o autor. Segundo Bakhtin, o autor pessoa, "é o elemento do acontecimento ético e social da vida" (2003, p. 9), ou seja, é quem escreve a obra, aquele que tem uma biografia na sociedade e pode ser considerado o artista responsável pelo texto. Por sua vez, o autor criador é um "elemento da obra" (2003, p. 9).

Acrescida a esses conceitos sobre autoria temos a noção de refração: "toda refração ideológica do ser em processo de formação, seja qual for a natureza de seu material significante, é acompanhado de uma refração ideológica verbal, como fenômeno obrigatoriamente concomitante" (BAKHTIN; VOLOSHINOV, 2006, p. 26), assim o signo reflete e refrata ${ }^{2}$ a realidade em transformação que está em contínua transformação (BAKHTIN; VOLOSHINOV, 2006). O autor pessoa, ao refratar através do signo linguístico o mundo no romance, o decompõe e o reorganiza. O autor criador, por sua vez, faz esse mesmo movimento com a personagem, e por isso é a consciência das consciências (BAKHTIN, 2003, p. 11). Nesta direção, podemos afirmar, pensando em Jane Austen:

\begin{abstract}
[ela] não só enxerga e conhece tudo o que cada personagem em particular e todas as personagens juntas enxergam e conhecem, como enxerga e conhece mais que elas, $\mathrm{e}$ ademais enxerga e conhece algo que por princípio é inacessível a elas, e nesse excedente de visão e conhecimento do autor, sempre determinado e estável em relação a cada personagem, é que se encontram todos os elementos do acabamento do todo, quer das personagens, quer do acontecimento conjunto de suas vidas, isto é, do todo da obra (BAKHTIN, 2003, p. 11).
\end{abstract}

O conceito de excedente de visão propõe que o autor criador olhe "de fora" daquele mundo que ele enforma para que, então, possa fazer o acabamento estético. No caso específico dos romances de Jane Austen, podemos apontar, no mínimo, três excedentes de visão. Primeiro, a autora pessoa que escreveu sobre sua contemporaneidade e refrata isso em suas obras. Segundo, a autora criadora enforma o objeto artístico e dá a ele o acabamento estético. O terceiro, por fim, trata das contemporaneidades que recepcionaram os romances ao

\footnotetext{
${ }^{2}$ A refração nos lembra um raio de luz que se decompõe ao atravessar uma gota d'agua, gerando o efeito prismático.
} 
longo dos quase dois séculos e acrescentaram novas possibilidades de leitura, interpretação e tradução do texto.

Dessa forma, compreendemos que a obra literária surge de uma organização dos eventos testemunhados por quem se apresenta como autor pessoa. Por sua vez, o autor criador, como responsável pelo todo estético do texto e pelos valores que ele congrega, o atualiza em outras vertentes axiomáticas, em outras culturas, e é capaz de sustentar essa atualização em contextos distintos.

Essa questão é fulcral para pensarmos sobre o grande tempo das artes na cultura. Quando Bakhtin, no texto "Metodologia das ciências humanas", discute a respeito dos contextos distantes, ele aponta duas noções temporais: "o pequeno tempo - a atualidade, o passado imediato e o futuro previsível - e o grande tempo - o diálogo infinito e inacabável em que nenhum sentido morre" (2003, p. 409). No caso de Austen, o pequeno tempo está próximo de sua época, envolve a primeira recepção, "vive" até o momento em que a autora pessoa biográfica morre e acompanha as repercussões desse fato. Após um certo tempo, as obras literárias começam a avançar de outra maneira, guiadas pelo grande tempo das artes. Essa reverberação se torna fundamental para mediar o diálogo entre obra e leitor nos diferentes contextos em que ela é recebida: “o autor é para o leitor o conjunto dos princípios criativos que devem ser realizados" (BAKHTIN, 2003, p. 192). A individualização do leitor já confere a ele um ato criador secundário independente do princípio ativo do autor criador (BAKHTIN, 2003, p. 192).

Consideramos os leitores, acima de tudo, como indivíduos que respondem à obra de Austen dentro do pequeno e do grande tempo e em perspectiva dialógica, à medida que a compreensão de um certo texto implica na resposta a ele, seja por meio de um simples debate, uma ilustração, uma mídia e até mesmo num artigo acadêmico. Concebemos, então, que "cada palavra (cada signo) do texto leva para além dos seus limites. Toda interpretação é o correlacionamento de dado texto com outros textos. O comentário. A índole dialógica desse correlacionamento" (BAKHTIN, 2003, p. 400). Esse pensamento nos revela que "cada palavra do texto se transfigura em um novo contexto" (BAKHTIN, 2003, p. 404). O signo, nesse caso, é o mesmo de sua primeira enunciação, mas o sentido depende do momento de sua interpretação.

A obra literária transita pelo grande tempo da cultura, ela "surge num presente, mas não se alimenta apenas de sua atualidade" (MACHADO, 1998, p. 35). Quando um artista responde ao texto de Austen, ele o está alimentado com sua atualidade, sua 
contemporaneidade. Essas respostas se conectam a outras que foram dadas em outras épocas e meios. Isso revela que "a vida não é algo acabado, mas um processo que não cabe nos limites das leis causais" (MACHADO, 1998, p. 35). O autor criador pode dar um acabamento estético à obra à medida em que ela é recepcionada, no entanto, por estar no grande tempo, ela nunca estará acabada, pois cada recepção revelará algo novo, que já estava lá quando o autor pessoa escreveu, mas somente é possível de ser descoberto com a atualização do autor criador. Com a transfiguração da palavra.

No pensamento de uma estética da criação cinematográfica, em que a tradução coletiva e o cinema literário funcionam como dois pilares, compreendemos o campo da cultura e sua profusão de signos como um campo de fronteiras. Se, no âmbito da literatura, em livro, a relação entre autor, narrador e personagens se complexifica, no âmbito do livro, em tela, estes elementos articulam-se com os agentes (recepção criativa) envolvidos. Tradução coletiva em livro, ilustração, projeto editorial, atualização do raciocínio do autor; tradução coletiva: os recursos midiáticos da época, os conjuntos humanos que se mobilizam à roda de um mesmo tema para a produção, realização, captação, finalização, veiculação - tudo isso em signos vivos. Tudo isso em uma rede inacabada de transfigurações nas quais a palavra viva se alimenta do sentido transitório.

\section{Jane Austen em ilustrações}

Entendemos que "o objetivo de toda a arte visual é a produção de imagens" (DALLEY, 1980, p. 10). No que concerne à conjugação entre livro literário e ilustração, temos algumas distinções. Em Livro ilustrado: palavras e imagens, Maria Nikolajeva e Carole Scott definem que, nos livros ilustrados, a imagem e o texto se situam na mesma plataforma de valor estético. Por sua vez, nos livros com ilustração, "o texto existe de modo independente" (NIKOLAJEVA; SCOTT, 2011, p. 21), mas se imiscui com a imagem para reinventar-se - há algo de publicística folhetinesca, marca da circulação do romance no Século XIX. Temos em mira que os romances de Jane Austen são originalmente sem as imagens, estas foram acrescidas, como dissemos, na década de 1890 a partir do projeto do grupo Macmillan (editora inglesa fundada em 1843) em Londres e Nova York.

Essas edições ilustradas nos fazem inferir sobre a questão da reprodutibilidade do romance ainda no século XIX, pensando com Benjamim (2010). Esse trabalho estético da criação verbal era problematizado por inúmeros escritores em diversos países. Nesse âmbito, o texto austeniano tinha a acrescentar, principalmente, às noções realistas que eram buriladas no final do XIX. Além disso, no plano editorial, o crescimento do público leitor influenciou as 
novas edições, motivando a oferecerem novidades que se conectassem com os meios de propagação da cultura e se diferenciassem de publicações anteriores das mesmas obras. Esses dois fatos preconizam que Austen se propagara pelos meios de consumo da arte.

No âmbito artístico visual, o ilustrador irlandês Hugh Thomson, entre 1894 e 1898, fez uma série de desenhos digamos, austenianos. Segundo Roger Chartier, "cada forma, cada suporte, cada estrutura da transmissão e da recepção do escrito afeta profundamente seus possíveis usos e interpretações" (2003, 44). Neste sentido, em diálogo com Bakhtin, ampliando o pensamento de uma estética da criação semiótica. Caracteriza o trabalho do ilustrador a renovação das palavras de Austen com a arte visual.

Assim, ilustrar um romance de Austen se apresenta como algo delicado, pois ela não oferece muitas descrições dos personagens ou dos lugares. Seus romances concentram-se muito na conversação e na coerência-cadência dos diálogos entre as pessoas (GANDARA, 2015). Estes detalhes nos trazem duas reflexões pontuais. A primeira trata da necessidade de detalhes para o leitor do final do XIX, imerso em um novo contexto citadino e distante da Inglaterra rural retratada e boa parte das obras. A segunda se refere à circulação da obra de Austen no cinema ser facultada, dentre outras coisas, justamente por esta força dialogal. Assim, temos a ilustração que complementa o texto literário e o filme que traduz o texto em imagem.

O ilustrador deve "auxiliar e complementar uma história, para que seja possível imaginar e criar um espaço para a acção" (RIBEIRO, 2011, p. 36). Thomson, no seu processo de criação, utilizou seu excedente de visão com as necessidades editoriais de sua época, compondo, no grande tempo das artes uma Jane Austen continuada e renovada. Tendo em vista que as ilustrações foram encomendadas exclusivamente para os livros, podemos considerar que Thomson foi um dos primeiros tradutores visuais da autora inglesa. Ele, de algum modo, contribuiu para a coletividade que traduziu os romances para o cinema, pois sua caracterização imagética certamente tornou-se referência para as pesquisas que envolvem cenários, figurinos, dentre outros campos semióticos. A seguir, um quadro com ilustrações de Thomson: 
Figura 1 - Ilustração de Orgulho e preconceito feita por Hugh Thomson (1894)

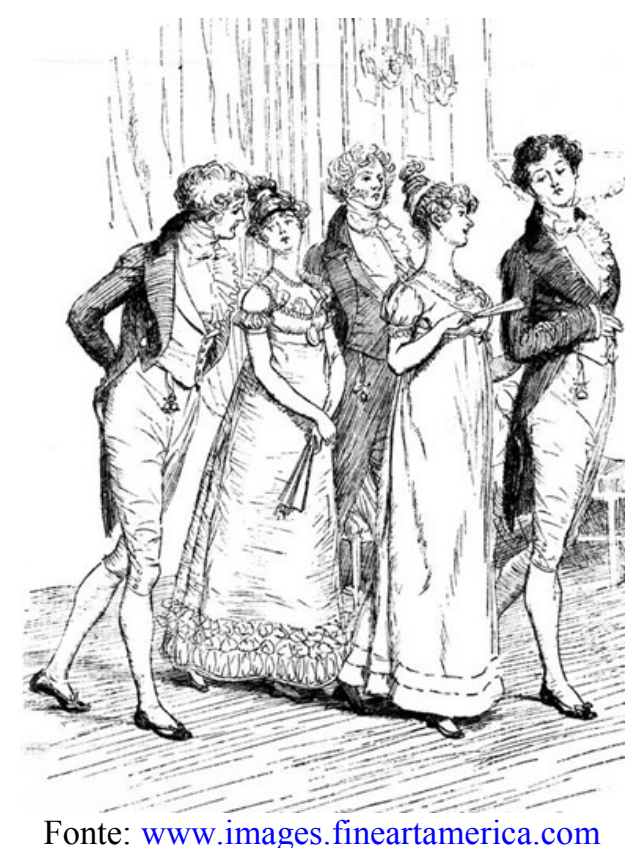

Figura 3 - Ilustração de Emma feita por Hugh Thomson (1896)

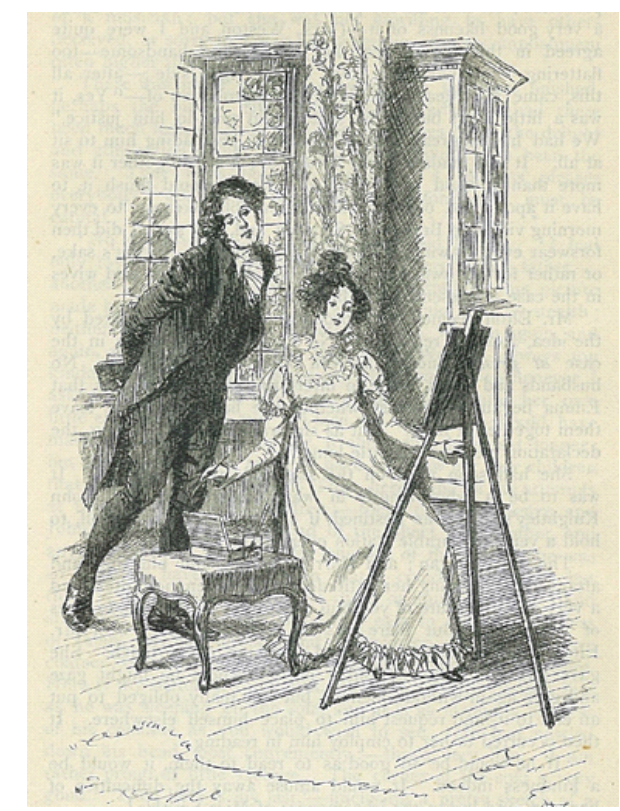

Fonte: www.nevsepic.com.ua/
Figura 2 - Ilustração de Razão e sentimento feita por Hugh Thomson (1896)

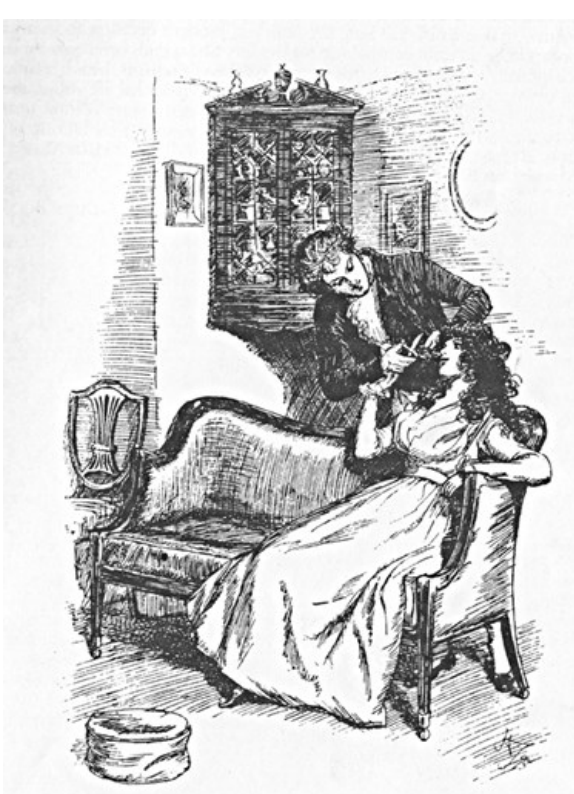

Fonte: www.kipet.files.wordpress.com

Figura 4 - Ilustração de Persuasão feita por Hugh Thomson (1898)

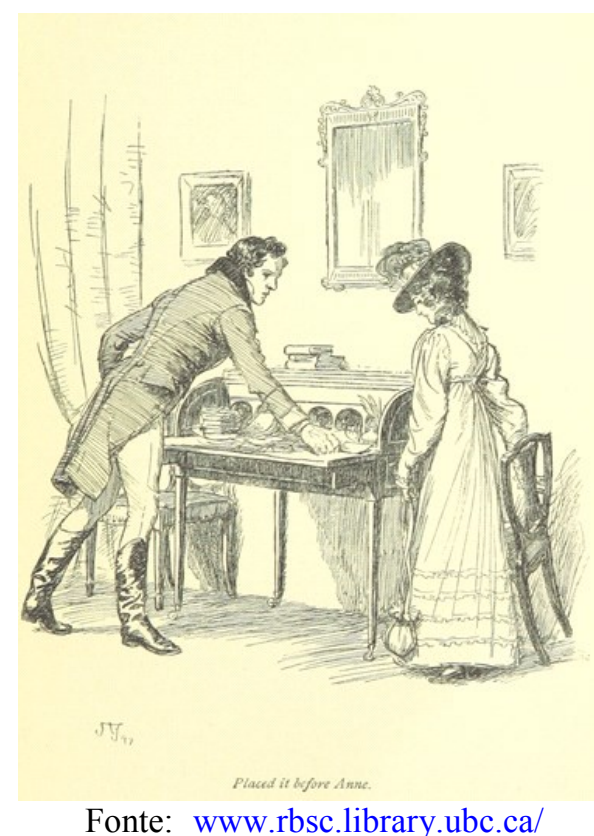

Na figura 1, de Orgulho e preconceito, temos a entrada do Senhor Bingley e seus acompanhantes na sua primeira festa em Hertfordshire: "quando o grupo entrou no salão, consistia apenas em cinco pessoas: Mr. Bingley, suas duas irmãs, o marido da mais velha e 
outro rapaz" (AUSTEN, 2010, p. 17). Na ilustração, percebemos o movimento dos personagens como se caminhassem em direção ao salão de baile. A distribuição dos rapazes e das moças também permite o leitor nomear cada um a partir do texto. À frente do grupo, estão o Sr. Hurts com a esposa, irmão de Bingley, que é o último; ele conversa com a sra. Bingley. Darcy, o "outro rapaz", se encontra no meio dos dois casais. A primeira vez que ele surge no romance é de forma pouco percebida, por parte do narrador, assim como na ilustração, na qual ele está envolto pelos casais e apresenta traços em nanquim que obscurecem ainda mais sua aparição. O detalhe das calças brancas dos homens à frente, o movimento dos vestidos e leques contrapõe-se à posição do corpo do personagem (que se tornará o principal na obra). Ele está ereto com o olhar distante, como se as coisas que (ainda) estão por vir nada lhe interessassem. Coisas futuras que o ilustrador já conhece bem, ao contrário do seu leitor folhetinesco.

A figura 2 é uma das mais significativas entre as ilustrações de Razão e sentimento, refere-se ao instante que Willoughby corta uma madeixa do cabelo de Marianne. No romance, Margaret testemunha o momento e, depois, conta a Elinor: "ontem à noite após o chá, quando você e mamãe saíram da sala, eles ficaram falando baixinho e rápido, e ele parecia estar pedindo a ela algo de seu, quando de repente apanhou a tesoura e cortou um longo anel de seus cabelos, que lhe caía pelas costas" (AUSTEN, 2011, p. 82). O ato foi visto pela menina, que estava presente na sala, e surge na obra como relato feito à irmã e confirmado, mais tarde, pela própria Marianne. Enquanto ilustrador, Thomson desloca o olhar de Margaret para o olhar do leitor, teatralizando a cena, e procura concentrar toda a ação na ocasião que antecede o corte do cabelo. Assim, temos a tesoura semiaberta e uma das mãos de Marianne encostada na mão do rapaz. Essa cena já prevê que ele fará a moça sofrer, principalmente pela forma com que "de repente" ele "corta" as relações amorosas suscitadas na alma apaixonada dela.

A figura 3, extraída do romance Emma, se passa na sessão de pintura em que Harriet posa para a protagonista: "Nada havia que se pudesse fazer em relação ao Sr. Elton, que andava irrequieto por trás dela, observando cada um de seus traços" (AUSTEN, 2011, p. 49). $\mathrm{Na}$ ilustração de Thomson, o Sr. Elton se inclina para ver a pintura enquanto se prepara para colher, com o pincel, mais uma dose de tinta. O espaço da casa é amplo, atmosfera diurna,

\footnotetext{
${ }^{3}$ when the party entered the assembly room it consisted of only five altogether-Mr. Bingley, his two sisters, the husband of the eldest, and another young man (AUSTEN, 2012, p. 10).

${ }^{4}$ Last night after tea, when you and mama went out of the room, they were whispering and talking together as fast as could be, and he seemed to be begging something of her, and presently he took up her scissors and cut off a long lock of her hair, for it was all tumbled down her back (AUSTEN, 2012, p. 48).

${ }^{5}$ There was no doing any thing, with Mr. Elton fidgeting behind her and watching every touch (AUSTEN, 2012, p. 34).
} 
móveis compondo a cena. O narrador informa a ação e quem está nela, coube ao ilustrador, conforme o destacado por Ribeiro (2011), criar o cenário, com acréscimos de objetos: o banco, os pinceis, a mesa, o cavalete e a tela pequena - já que se tratava de um retrato de Harriet.

Por sua vez, no romance Persuasão, a figura 4 ilustra a declaração de amor que o Capitão Wentworth faz a Anne em forma de carta: "Pediu desculpas, pois havia esquecido as luvas, e na mesma hora atravessou a sala até a mesa de escrever, e ali em pé, com as costas viradas para a sra. Musgrove, tirou uma carta do meio dos papéis espalhados e pôs diante de Anne" uma sala na casa dos Musgrove e que há uma mesa de escrever, além da carta. No entanto, o ilustrador adiciona a cadeira. Pelo movimento declinado do móvel, podemos interpretar que Elliot levantou às pressas e assustada. $\mathrm{O}$ olhar da moça está voltado para a carta e o dele confirma o remetente - enquanto a cadeira dança desconcertada e cúmplice.

As quatro ilustrações surgem nos respectivos romances de forma a contribuir com a cena e com a composição da imagem pelo leitor. Em algumas, há breves inscrições, como em Persuasão, que está escrito "Placed it before Anne"; em outras os ilustradores procuram seguir as direções do narrador, como em Orgulho e preconceito. As ilustrações de Emma e Razão e sentimento revelam um excedente de visão no qual Thomson teve que ilustrar a partir de pistas dadas pelos personagens ou pelo narrador. Outro fato que converge o diálogo entre as ilustrações são os espaços privados e a composição dos trajes. Nesse caso, devemos frisar que Thomson ilustrou no final de século XIX e o acesso às noções de moda e decoração advêm, em grande parte, das pinturas feitas no início do mesmo século, tendo-se em vista que a fotografia surgira apenas na segunda metade do dezenove e sua ampla circulação na mídia se deu realmente no começo do século XX.

Projetamos nosso raciocínio nos vestidos, com a cintura império, trajados pelas mulheres. Podemos afirmar que eles se assemelham àqueles elaborados para os filmes em questão. Isto que reforça o diálogo entre as ilustrações e o audiovisual. Além disso, essas peças se tornaram uma marca peculiar da era georgiana, bem como do universo literário de Austen traduzido para outras mídias.

As ilustrações já indicam o movimento das imagens geradas a partir dos romances de Austen. Os filmes realizados entre 1995 e 2005 trazem a moda do campo e da cidade, pois as

\footnotetext{
${ }^{6}$ He begged their pardon, but he had forgotten his gloves, and instantly crossing the room to the writing table, he drew out a letter from under the scattered paper, placed it before Anne (AUSTEN, 2012, p. 202, grifo nosso).
} 
heroínas se vestem de acordo com o universo social que frequentam. Os espaços, que surgem como coadjuvantes nas ilustrações, serão retomados de forma mais profunda, principalmente no que concerne às grandes mansões dos proprietários rurais ingleses. Outro aspecto é o traço que Thomson usou nos rostos dos personagens. A face quase sempre ovalada e o cabelo cacheado reforçam a noção de beleza e moda fundamentados no estilo clássico grego. As edições ilustradas permitiram aos leitores do final de século XIX (e dos séculos seguintes) reconstituírem um pouco do que eram as relações com o espaço e com a idealização de beleza e poder nas décadas de 1800 e 1810.

Os livros com ilustrações de Thomson revelam como o artista interpretou partes do texto literário. Compondo, por metonímias ilustrativas, uma aura para o(a) leitor(a) de seu tempo. Uma vez que a autora pessoa já não existia mais, o ofício artístico de Thomson foi guiado pela autora criadora presente no acontecimento estético do texto. No dezenove, a união mais provável entre literatura e imagem era por meio da ilustração. Por sua vez, no século $\mathrm{XX}$, o cinema se desenvolveu e difundiu a prática das traduções coletivas, genericamente conhecidas como adaptação.

\section{A estética da criação cinematográfica em Jane Austen}

A relação entre o cinema e a literatura atravessa toda a história da sétima arte. Desde o princípio a arte com palavras foi referência para a arte com câmeras. Conceituamos o diálogo entre essas duas artes como cinema literário, que "parte da obra escrita e tudo aquilo à sua volta e 'responde' artisticamente por meio do visual, do sonoro e da tela" (SILVA JUNIOR; GANDARA, 2014, p. 358). No interior desse construto, a tradução coletiva trata do encontro de diversas leituras de um mesmo texto traduzidas nas inúmeras funções que uma produção fílmica exige.

A tradução coletiva no cinema literário exige várias visões, múltiplas vozes e uma multiplicidade de ações. O resultado de um filme em sua projeção foi composto por várias etapas durante a concepção da obra, o que evidencia a coletividade. É notável que todos os envolvidos reverberam na obra. O cinema é a arte que ao final apresenta inúmeros nomes, lugares, instituições. É mesmo uma arte mobilizadora de coletividades. Decupemos estas funções dos modos de fazer cinematográfico: a trilha sonora é resultado de uma leitura musical; a fotografia, articulação das cores e luzes, a sonoplastia é uma leitura criativa do som, a interpretação é um fazer corporal e vocal do literário - não exatamente para o público, mas para pessoas e máquinas captadoras -; o roteiro é uma leitura criativa do texto verbal seu espelho, seu duplo, sua outra face (SILVA JUNIOR; GANDARA, 2013, p. 84).

Anu. Lit., Florianópolis, v. 20, n. 2, p. 67-83, 2015. ISSNe 2175-7917 
Sendo assim, no filme, diversas leituras se desdobram no excedente de visão facultado pela respondibilidade. Motivado pelo contato íntimo com a obra literária e montado (mais um processo fazedor), tendo em vista um efeito homogêneo para a plateia (mais uma etapa - no escurinho da sala, no televisor, no écran do computador, no celular...). Dessa forma, as cenas escritas por Austen e ilustradas por Thomson também foram traduzidas para o cinema. Eis, abaixo, as mesmas passagens que citamos enformadas em imagem fílmica:

Figura 5 - Cena de Orgulho e preconceito (metragem 00:06:53)

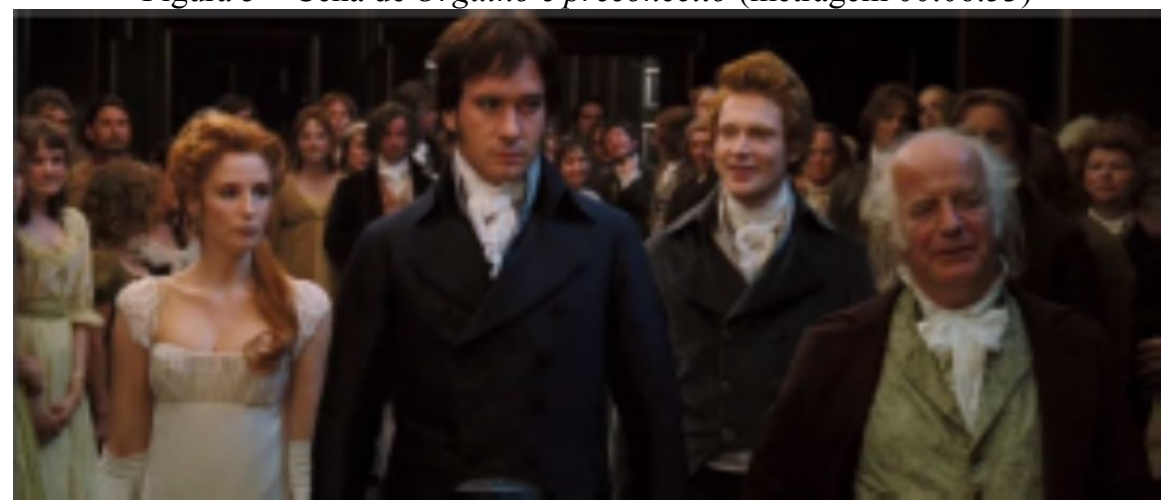

Fonte: Filme Orgulho e preconceito. Direção: Joe Wright. Inglaterra, 2005.

Figura 6: Cena de Razão e sensibilidade (metragem 00:52:02)

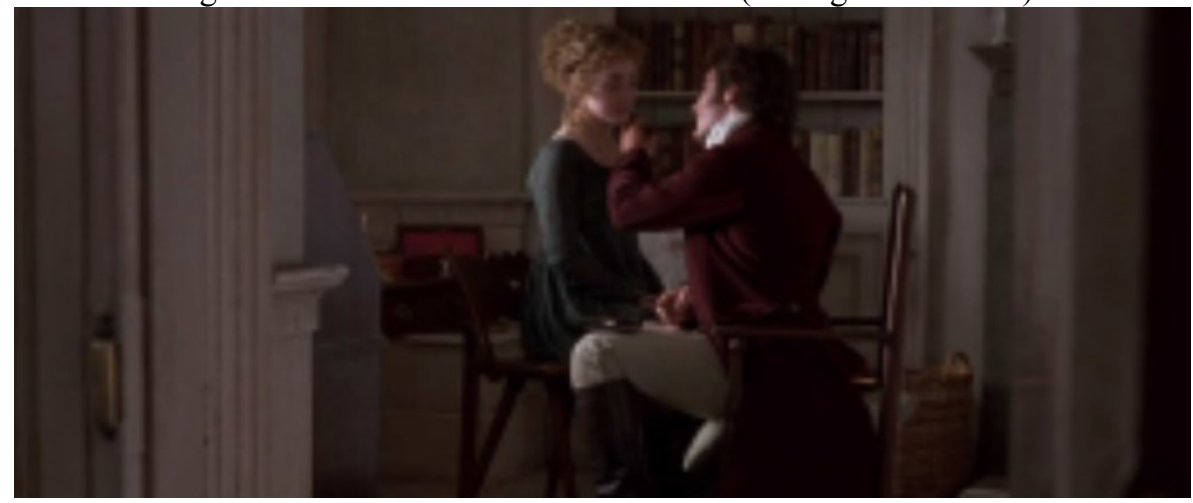

Fonte: Filme Razão e sensibilidade. Direção: Ang Lee. Inglaterra, 1995.

Figura 7 - Cena de Emma (metragem 00:17:11)

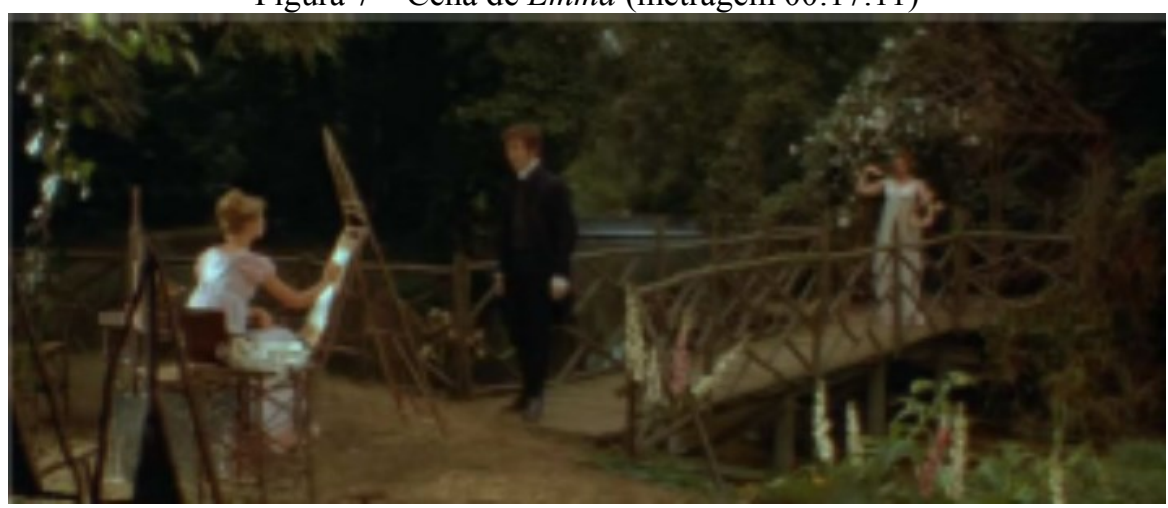

Fonte: Filme Emma. Direção: Douglas McGrath. EUA, 1996. 
Figura 8 - Cena de Persuasão (metragem 01:37:18)

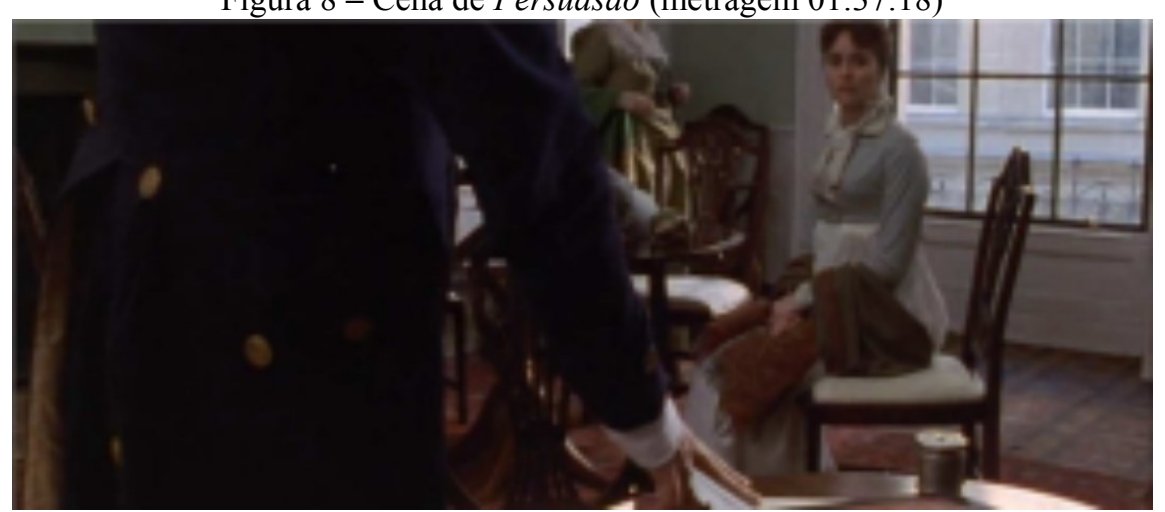

Fonte: Filme Persuasão. Direção, Roger Michell. Inglaterra, 1995.

O signo linguístico deu origem às ilustrações e aos filmes. Há semelhanças nas duas composições visuais, mas também há grandes distanciamentos. Na tradução coletiva do cinema literário, a imagem ganha iluminação fotográfica, atores, figurinos, maquiagem, enquadramentos, cenários, sons, expectadores. Ao compararmos as duas versões visuais do texto, chegamos a algumas considerações sobre a elaboração das cenas. Na figura 5 , do filme Orgulho e preconceito (Pride and Prejudice, Joe Wright, ING, 2005), temos uma aproximação, no que tange ao ambiente do Baile dos Lucas, com a figura 1. No entanto, o número de personagens diminui, saem a irmã mais velha do Sr. Bingley e o esposo. O Sr. Darcy, que estava praticamente escondido, ganha o centro da imagem. No cinema, essa mise en scéne realça o protagonismo do personagem, seu status social e seu ar circunspeto - no maxilar enrijecido. Enquanto Thomson aproxima-se da proposta mais, digamos, reliteral do texto, o filme se distancia para causar um efeito de poder e tensão envolto de Darcy, uma figura, neste momento da trama, cercada de mistérios para a sociedade Netherfield.

A figuras 6, do filme Razão e sensibilidade (Sense and Sensibility, Ang Lee, ING, 1995), tem o mesmo cenário e os mesmos personagens. Porém, se a confrontarmos com a ilustração de Thomson, a posição de Willoughby é invertida. Ele está de joelhos e acaricia o rosto de Marianne. Isso deixa a ato mais erótico, pois há um toque íntimo entre eles numa profunda troca de olhares. Diferente da cena teatralizada, na figura 2, e da passagem literária, no filme, é Elinor quem presencia o momento de carinho entre os amantes. Assim, temos a mesma cena, porém trabalhada artisticamente por três ângulos dispares.

Essa sutileza que confirma de onde parte o olhar na cena está, também, na figura 7, de Emma (Douglas McGranth, EUA, 1996). Tal qual na ilustração (fig. 3), a equipe de direção de arte teve que criar um espaço para receber o momento em que Emma pinta um retrato de Harriet. Enquanto o ilustrador prefere o espaço interno da mansão onde vive a personagem, no filme a preferência é pelo exterior. Além disso, Harriet aparece na cena que 
está em plano aberto. A fotografia permite que o quadro seja encenado. No filme, para-além da tela pintada pela personagem, o personagem masculino adentra não o quadro, mas o enquadramento.

Por fim, a figura 8 tem uma composição muito parecida com as duas que a precedem - no caso, texto de Austen e figura 4. Na cena do filme Persuasão (Persuasion, Roger Michell, ING, 1995), o capital Wentworth mostra a sua amada Anne Elliot onde está a carta de amor que ele escrevera a ela. A cena é rápida e muito sutil. A câmera está discretamente posicionada atrás da escrivaninha e capta a reação de Anne ao fundo e a mão de Wentworth indicando a carta centralizada em primeiro plano. Apesar de haver mudanças na mise en scène, tanto na ilustração, quanto no filme, o objetivo é o mesmo, colocar a carta diante de Anne (placed it before Anne).

Com as comparações, percebemos como os leitores ativos dos romances movimentaram suas leituras em distintas artes visuais. Thomson começou a ilustrar os livros nas vésperas da invenção efetiva do cinema, ocorrida em 1895, e terminou quando essa arte começava a caminhar de modo independente. Cem anos depois desse acontecimento, os filmes Razão e sensibilidade e Persuasão trazem Austen para dialogar com o final do século $\mathrm{XX}$. As mulheres que tanto dialogam nos livros de Austen reaparecem, revolucionárias, mas não menos casadoiras. Essa tradução do signo literário em outras artes, na melhor perspectiva bakhtiniana, reforça a refração dos romances da autora nos contextos que a receberam e estimularam sua continuidade. Esta vertente do cinema literário, em diálogo com a (pesquisa da) ilustração nos dão uma compreensão das várias camadas de realização de cada cena de um filme. Desta forma mapeamos vínculos entre três momentos na história cronológica, evidenciado, assim, um fértil diálogo entre as obras, seus desdobramentos mediados por leitores, leituras e ressignificações.

\section{Considerações finais}

O texto literário, as ilustrações e as imagens fílmicas estão localizados, historicamente, em distintas épocas. Nelas, eles fluíram ao sabor de seu tempo e segundo os signos em que foram enunciados. Austen escreveu na Inglaterra rural e foi publicada anonimamente visando apenas o entretenimento de suas leitoras. Já no final do século XIX, sua obra é elevada ao cânone da língua inglesa. Nesse contexto, ganham os traços ilustrativos de Thomson, que dá os primeiros índices visuais aos romances da autora. No século XX, a serviço de um projeto em que a cultura e história da Europa são resgatadas no cinema pelos 
filmes patrimonialistas (heritage films), todas as suas obras são retomadas e despertam, novamente, novos leitores para além dos territórios da rainha.

O movimento iniciado quando da escrita dos livros e das primeiras edições se fortificou com o passar dos anos e dos séculos. A apropriação dos textos literários de Austen feita por outros meios sígnicos possibilitou o avanço em distintos contextos de recepção e em diferentes meios de arte e reprodução. Esse diálogo foi possível graças à autora criadora que sustenta a obra nas múltiplas circunstâncias em que é recebida, aos leitores-tradutores ativos que traduziram suas interpretações em outra arte, seja por meio do nanquim de Thomson ou dos artistas envolvidos nas traduções coletivas para o cinema. Estes últimos, num panorama dialógico no campo da criação estética cinematográfica, revela o inacabamento do texto austeniano e desperta novas leituras possíveis dentro do grande tempo das artes.

\section{Referências}

AUSTEN, J. Emma. Nova York: Sterling Publishing, 2012.

. Emma. Trad. de Ivo Barroso. Rio de Janeiro: Nova Fronteira, 2011.

. Orgulho e preconceito. Trad. de Lúcio Cardoso. São Paulo: Abril, 2010.

. Persuasão. Trad. de Fernanda Abreu. Rio de Janeiro: Zahar, 2012.

. Persuasion. Nova York: Sterling Publishing, 2012.

. Pride and Prejudice. Nova York: Sterling Publishing, 2012.

. Razão e sentimento. Trad. de Ivo Barroso. Rio de Janeiro: Nova Fronteira, 2011.

. Sense and Sensebility. Nova York: Sterling Publishing, 2012.

BAKHTIN, M; VOLOSHINOV, V. Marxismo e filosofia da linguagem. Trad. de Michel Lahud e Yara Frateschi Vieira. São Paulo: Hucitec, 2006.

BAKHTIN, M. Estética da criação verbal. Trad. de Paulo Bezerra. São Paulo: Martins Fontes, 2003.

Questões de literatura e de estética: a teoria do romance. Trad. de Aurora Fornoni Bernardini et al. São Paulo: Unesp, 1998.

CHARTIER, R. Formas e sentido, cultura escrita: entre distinção e apropriação. Campinas: Mercado de Letras, Associação de Leitura do Brasil, 2003.

DALLEY, T. Ilustración y diseño. Madri: Herman Blume, 1980. 
GANDARA, L. C. Jane Austen no cinema literário: tradução coletiva e dialogismo no grande tempo das artes. 2015. 125 f. Dissertação (Mestrado em Literatura). Instituto de Letras, Universidade de Brasília, Brasília, 2015.

MACHADO, I. A. Narrativa e combinatória dos gêneros prosaicos: a textualização dialógica. Revista Itinerários, São Paulo, ano 12, p. 33-46, 1998.

NIKOLAJEVA, M.; SCOTT, C. Livro ilustrado: palavras e imagens. Trad. de Cid Knipel. São Paulo Cosac Naify, 2011.

RIBEIRO, M. S. D. Do desenho à ilustração infantil. Dissertação (Mestrado em desenho), Faculdade de Belas Artes, Universidade de Lisboa, Lisboa, Portugal, 2011.

SILVA JUNIOR, A. R.; GANDARA, L. C. Bakhtin e cinema: tradução coletiva e dialogismo em Orgulho e preconceito de Jane Austen. In: II ENCONTRO DE ESTUDOS BAKHTINIANOS: VIDA CULTURA E ALTERIDADE, 2, 2013, São Carlos. Encontro Bakhtiniano com a Vida e as Esferas Culturais. EEBA/2013 - Caderno 3. São Carlos: Pedro e João editores, 2013. p. 83-88.

O cinema literário brasileiro: Abril despedaçado, uma tradução coletiva. In: VII SEMINÁRIO NACIONAL DE PESQUISA EM ARTE E CULTURA VISUAL, 7, 2014, Goiânia. Anais do VII Seminário Nacional de pesquisa em arte e cultura visual. (2014). Goiânia: UFG, FAV, 2014. p. 356-365.

\section{Referências fílmicas}

EMMA. Direção: Douglas McGrath. EUA, 1996. 121 minutos.

ORGULHO E PRECONCEITO (Pride and Prejudice). Direção: Joe Wright. Inglaterra, 2005. 129 minutos.

PERSUASÃO (Persuasion). Direção: Roger Michell. Inglaterra, 1995. 107 minutos.

RAZÃO E SENSIBILIDADE (Sense and Sensibility). Direção: Ang Lee. Inglaterra, 1995. 131 minutos.

\section{Créditos das imagens}

Figura 1, Ilustração de Orgulho e preconceito feita por Hugh Thomson (1894)

Figura 2, Ilustração de Razão e sentimento feita por Hugh Thomson (1894)

Figura 3, Ilustração de Emma feita por Hugh Thomson (1894)

Figura 4, Ilustração de Persuasão feita por Hugh Thomson (1894)

Figura 5, cena do filme Orgulho e preconceito (2005)

Figura 6, cena do filme Razão e sentimento (1995)

Figura 7, cena do filme Emma (1996) 
Figura 8, cena do filme Persuasão (1995)

[Recebido em maio de 2015 e aceito para publicação em agosto de 2015]

\section{Translation Collective and Illustration: Aesthetic Film Creation from Jane Austen}

Abstract: From metonymic clippings of the novels Sense and Sensibility (1811), Pride and Prejudice (1813), Emma (1815) and Persuasion (1817), all written by the English author Jane Austen (1775-1817), we propose a comparative analysis among the literary texts, the illustrations by Hugh Thomson at the end of the nineteenth century and the film footage created between 1995 and 2005. Our goal is to confront tickets to find similarities and differences dialogic between them. This perspective reveals the interpretations made by many readers over the years and the receptions of the English writer in different contexts and media. Our critical and theoretical reflection is based on studies of the Russian philosopher Mikhail Bakhtin about the aesthetics of literary creation and amplifies the concepts of literary cinema, collective translation and aesthetics of film creation.

Keywords: Jane Austen. Illustration. Mikhail Bakhtin. Translation collective.

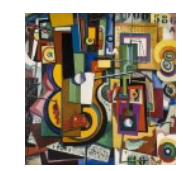

